\title{
Spatial memory in the grey mouse lemur (Microcebus murinus)
}

\author{
Mia-Lana Lührs · Melanie Dammhahn • \\ Peter M. Kappeler · Claudia Fichtel
}

Received: 12 February 2008/Revised: 10 February 2009/Accepted: 11 February 2009/Published online: 5 March 2009

(C) The Author(s) 2009. This article is published with open access at Springerlink.com

\begin{abstract}
Wild animals face the challenge of locating feeding sites distributed across broad spatial and temporal scales. Spatial memory allows animals to find a goal, such as a productive feeding patch, even when there are no goalspecific sensory cues available. Because there is little experimental information on learning and memory capabilities in free-ranging primates, the aim of this study was to test whether grey mouse lemurs (Microcebus murinus), as short-term dietary specialists, rely on spatial memory in relocating productive feeding sites. In addition, we asked what kind of spatial representation might underlie their orientation in their natural environment. Using an experimental approach, we set eight radio-collared grey mouse lemurs a memory task by confronting them with two different spatial patterns of baited and non-baited artificial feeding stations under exclusion of sensory cues. Positional data were recorded by focal animal observations within a grid system of small foot trails. A change in the baiting pattern revealed that grey mouse lemurs primarily used spatial cues to relocate baited feeding stations and that they were able to rapidly learn a new spatial arrangement.
\end{abstract}

Electronic supplementary material The online version of this article (doi:10.1007/s10071-009-0219-y) contains supplementary material, which is available to authorized users.

M.-L. Lührs $(\bowtie) \cdot$ P. M. Kappeler

Department of Sociobiology/Anthropology,

Johann-Friedrich-Blumenbach-Institute for Zoology

and Anthropology, University of Göttingen,

Berliner Strasse 28, 37073 Göttingen, Germany

e-mail: Mia-Lan@gmx.de

M. Dammhahn · P. M. Kappeler · C. Fichtel

Department of Behavioral Ecology and Sociobiology,

German Primate Center, Kellnerweg 4,

37077 Göttingen, Germany
Spatially concentrated, non-random movements revealed preliminary evidence for a route-based restriction in mouse lemur space; during a subsequent release experiment, however, we found high travel efficiency in directed movements. We therefore propose that mouse lemur spatial memory is based on some kind of mental representation that is more detailed than a route-based network map.

Keywords Spatial cognition - Topological map · Euclidean map - Correlated random walk .

Goal-directed movement $\cdot$ Microcebus murinus

\section{Introduction}

In the wild, animals are confronted with the problem of locating non-ephemeral resources that are variably distributed in space and time. Solving the problem of relocating dispersed food resources requires the ability to integrate spatial, temporal and ecological information. Spatial memory enables animals to relocate widely distributed food patches (e.g. bees: Dyer 1996; hummingbirds: Gónzalez-Gómez and Vásquez 2006; Healy and Hurly 1995; bats: Thiele and Winter 2005; rats: Langley 1994), to remember the positions of food caches (e.g. food-storing birds: Balda et al. 1998; Herz et al. 1994; Shettleworth 1990), to select productive feeding sites over non-productive or recently depleted sites, and to minimize the distances travelled among those sites (Anderson 1983; Benhamou 1994). Thus, enhanced spatial memory capacities confer a selective advantage but the underlying mechanisms are not yet fully elucidated. Setting a course from one food patch to another requires an understanding of spatial relationships among features of the environment to each other and to the position of the animal itself 
(Gallistel 1989). In general, three basal mechanisms of spatial memory and their underlying spatial representations can be distinguished (Gallistel 1989, 1990; Garber 2000; Poucet 1993): path integration, the route-based network map and the Euclidean map. However, discrimination between different kinds of spatial representation is not always clear-cut, because a given species often uses several mechanisms simultaneously.

Path integration or dead reckoning has been studied in most detail in desert ants (genus Cataglyphis), which track their own movements from the nest by memorizing the corresponding distances and angles, and which can compute a direct homing route to their nest from any position in space (Wehner 2003). This kind of spatial memory is of special importance for central place foragers or species living in open habitat where visual landmarks are scarce. It has been described for other insects (e.g. Collett and Collett 2000; Dyer 1994; Wittlinger et al. 2006) and some vertebrates (Alyan and Jander 1994; Cattet and Etienne 2004; Etienne et al. 1996; Séguinot et al. 1993), including humans (Gallistel 1990; Loomis et al. 1993; Wang and Spelke 2002).

In contrast, the route-based network map or topological map is a mental representation of spatial relationships, which is a network of routes and landmarks, rather than a map (Byrne 1979; Garber 2000). Animals which represent spatial relationships in their environment in a route-based way (e.g. bees: Dyer 1991; Dyer et al. 1993; non-human primates: Di Fiore and Suarez 2007; Garber 2000; Garber and Jelinek 2005; Noser and Byrne 2007; humans: Byrne 1979) store relative positions of landmarks and other salient features of their environment to each other and rely on this set of points to reorient (Byrne 2000). Such a routebased pattern of space use is characterized by the existence of a network of commonly reused pathways between landmarks or nodes (Gallistel 1990; Poucet 1993).

A Euclidean map refers to the ability to mentally construct a map of geometric relationships in Euclidean space (O'Keefe and Nadel 1978). In contrast to a non-geometric route-based map, true angles and distances between landmarks are represented within some kind of coordinate system, which allows an animal to compute routes between points that are out of view and, thus, to bridge informational gaps (Gallistel 1990; Poucet 1993). The Euclidean map can serve as a base for planned navigation and offers the opportunity to move efficiently, allowing straight-line travel and short-cutting between points without dependence on other than spatial memory cues. Even though the existence of a Euclidean map is practically impossible to demonstrate (Benhamou 1996; Bennett 1996; Poucet 1993), it has been proposed to explain movement patterns in several taxa (e.g. humans: Gallistel 1990; Tolman 1948).

In primates, previous studies on foraging and ranging behaviour demonstrated straight-line travel and efficient goal-directed movement between distant sites, indicating detailed mental spatial representations in apes (Boesch and Boesch 1984; Menzel et al. 2002; Menzel 1973), old world monkeys (Altmann 1974; Cramer and Gallistel 1997; Janmaat et al. 2006; Menzel 1991) and new world monkeys (Garber and Hannon 1993; Garber and Jelinek 2005; Janson 1996, 1998). For the phylogenetically basal strepsirrhine primates, only preliminary behavioural data are available (e.g. Erhart and Overdorff 2008; Joly and Zimmermann 2007). In this paper, we contribute comparative data from an experimental study of spatial memory in a basal strepsirrhine, the grey mouse lemur (Microcebus murinus).

In western Madagascar, grey mouse lemurs inhabit the dry deciduous forests, a highly seasonal environment with pronounced fluctuations in food availability, which favours short-term dietary specialists and other ecological specializations (Radespiel 2006). In the long dry season, when food availability is low, mouse lemurs mainly rely on resources which are sparsely distributed but predictable in space, such as gum, homopteran secretions and nectar (Dammhahn and Kappeler 2008). Hence, the ability to relocate food resources ought to be selected for in the grey mouse lemur, a competence that might make this species' spatial capabilities comparable to those found in foodcaching animals (e.g. Gibson and Kamil 2001; Herz et al. 1994; see Shettleworth 1990 for a review).

The majority of studies on spatial memory and spatial representation in mammals have either been conducted in captivity (e.g. rodents: Benhamou 1996; primates: Beran et al. 2005; Cramer and Gallistel 1997; Menzel et al. 2002) or were based on observations of natural ranging and foraging behaviour (e.g. primates: Cunningham and Janson 2007; Garber and Jelinek 2005; Valero and Byrne 2007). Field experiments offer the advantage to observe animals in their natural environment while controlling variables of interest (Garber 2000; Janson 1996). There have been several insightful field experiments on primate spatial cognition (e.g. Bicca-Marques and Garber 2004; Garber and Paciulli 1997; Janson 1996, 1998), none of which, however, with strepsirrhine primates.

The aim of the present study was to investigate spatial memory performance in free-ranging grey mouse lemurs experimentally. In a feeding experiment, we confronted solitary individuals with an arrangement of seven feeding stations, only a part of which was baited, and subsequently recorded their movements among these stations. Controlling for olfactory cues, we used a change in the baiting pattern to investigate whether mouse lemurs remembered the positions of baited stations in space. Subsequently, we conducted release experiments to record the animals' movements from the point of release to the closest feeding station. Specifically, we investigated (1) whether grey 
mouse lemurs move in space randomly or show goaldirected behaviour, (2) whether they use spatial cues to find a goal, and if so, (3) what kind of spatial representation might underlie their spatial memory.

\section{Methods}

Study area and study subjects

The study was conducted from August to November 2006 in Kirindy Forest/CFPF, in central western Madagascar. Kirindy is a dry deciduous forest located about $60 \mathrm{~km}$ northeast of Morondava within a 12,500 ha concession of the Centre de Formation Professionelle Forestière (CFPF) de Morondava (Sorg et al. 2003). The climate of this area is characterized by pronounced seasonality with a hot rainy season from December to March and a dry season with little or no precipitation from April to November (Sorg and Rohner 1996). The study area, locally known as CS5, comprises about 26 ha and is equipped with a system of rectangular foot trails in $25 \mathrm{~m}$ intervals. Each trail intersection is marked for orientation and $x-y$-coordinates of intersections were used to create a map.

Grey mouse lemurs were captured in a 6 ha-part of the study area. Animals in this forest area are regularly captured and individually marked with transponders (Trovan, Usling, Germany). Two females (F1, F2) and six males (M1-M6) that were captured near the centre of the study area were briefly anesthetized (Rensing 1999) and equipped with small radio-transmitter collars (2 g, TW4, Biotrack, UK). Additionally, individuals were visually marked by an individual tail shaving pattern. All radiocollars were removed at the end of the study.

During 2 weeks before the onset of the experiment, individual home ranges were determined by rotational radio-tracking. Positions were taken as estimations of direction and distance from the nearest grid path intersection as a reference point and subsequently transformed into $x-y$-coordinates. To ensure independence among the positional data points, animals were radio-tracked consecutively with a minimum of 15 min between two records of the same individual (Swihart and Slade 1985). Whenever possible, positions were confirmed visually.

\section{Experimental design}

After determination of individual home ranges, areas of overlap among focal animals were chosen to install feeding stations. Seven feeding stations were arranged in a regular pattern (Fig. 1) in three different regions of the study area (subsequently referred to as regions $\mathrm{M}, \mathrm{R}$, and $\mathrm{U}$ ). The stations consisted of wooden platforms of about

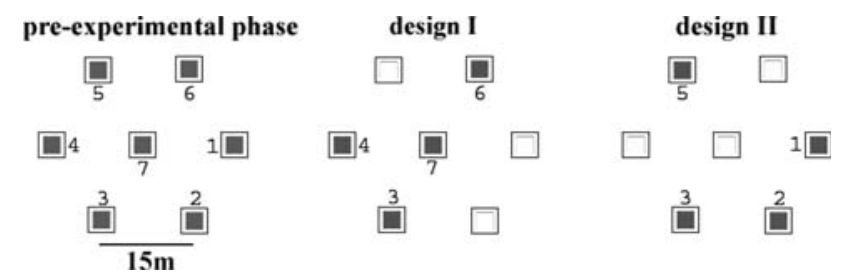

Fig. 1 Patterns of baited (filled) and non-baited (blank) feeding stations during the pre-experimental phase (left) and during experimental design I and II (centre and right), respectively. Numbers of stations are shown for baited stations only. Note that station no. 3 was continuously baited

$30 \mathrm{~cm} \times 30 \mathrm{~cm}$, which were fixed on a $1.5 \mathrm{~m}$ pile. About $15 \mathrm{~cm}$ above the platform, a plastic pipe was attached. The pipe was closed by a wire net below but open at its upper end, which allowed the fixation of a plastic pet drinking bottle.

Before the onset of the first experiment, all stations were baited right before sunset with a small amount of banana and some drops of sugary syrup to facilitate the perception of the stations by the animals and to habituate them to the feeding procedure (Fig. 1, left). After a 2-week baiting phase, the actual experiment started with design I, which was characterized by a baiting pattern that included only four stations (Fig. 1, centre). During the experiment, a 1:9 solution of syrup and water was used as bait with minimal olfactory cues.

Design I was run for 3 weeks. Subsequently, the baiting pattern was changed to design II (Fig. 1, right), which included three formerly non-baited and one formerly baited station (no. 3). This rotation of the baiting was carried out successively for each of the three regions (M, R, U) to observe focal animals directly after rotation of the baiting pattern. Observations were conducted at nights 1, 2, 3 and 5 after change from design I to II. At region $\mathrm{M}$ two animals (individuals M4, F1) were observed during nights 1, 2, 3 and 4 after change to avoid time overlap with the final capture phase. Due to predation or home range shift during the mating season, only five individuals could be subjected to design II.

\section{Observation protocol}

During the experiments, each radio-collared animal was followed for $90 \mathrm{~min}$ of focal animal sampling. These observation bouts were distributed evenly over the animals' peak activity time between 18:00 and 22:00 h (Rasoazanabary 2006). The focal animal's position was recorded instantaneously every minute by estimating its distance and direction to the nearest trail intersection. Additionally, height, behaviour and interactions with other animals were recorded instantaneously every minute to 
control for possible influences of these factors on the animals' movements. Each focal animal was followed for $2-5$ observation bouts per design (Table 1).

\section{Spatial analyses}

To investigate whether the experiment had an influence on ranging behaviour, individual home range kernels (Worton 1989) for each observation bout were calculated using ArcView GIS 3.2 (Esri) and Animal Movement Software (Hooge et al. 1999). These kernels were then compared with the corresponding kernel of the stations. Smoothing factors were chosen in a way that all regions of stations had approximately the same size. Overlaps for areas with 50 and $95 \%$ probability of utilization were calculated for each observational bout. Subsequently, we compared the extent of overlap between home range kernels and station kernels before and during the experiment, using Wilcoxon matched-pairs test. One animal (M1) was excluded from the analyses because no data were available from the time before the onset of the experiment. Another animal (M4) had to be excluded because of a general enlargement of its home range during the mating season.

We also calculated weighted means of individual home ranges during the observational bouts, using the ArcView GIS 3.2 (Esri) Weighted Mean extension (Jenness 2004), and compared the median weighted means of all observational bouts during the experiment with the weighted mean of the animal's home range before the onset of the experiment, using Wilcoxon matched-pairs test. Additionally, we compared positions of sleeping sites before and during the experimental phase for each individual. Since grey mouse lemurs regularly reuse a certain number of sleeping trees situated in their home range, one would expect to find a shift in the location of these trees towards the stations as a consequence of the shift of the animals' activity range. We compared median distances between sleeping sites before

Table 1 Focal animals and number of observation bouts (90 min each) per experimental design

\begin{tabular}{lllll}
\hline Focal animal & Sex & Site & No. bouts design I & No. bouts design II \\
\hline M1 & Male & R & 2 & - \\
M2 & Male & M & 3 & - \\
M3 & Male & R & 5 & 4 \\
M4 & Male & M & 4 & 4 \\
M5 & Male & R & 4 & 4 \\
M6 & Male & U & 4 & - \\
F1 & Female & M & 3 & 4 \\
F2 & Female & U & 4 & 4 \\
\hline
\end{tabular}

$R, M$ and $U$ denote the three sites within the study area where feeding stations were installed
( $n=9-10$ for each of six individuals) and during $(n=9$ 10) the experiment, using the Wilcoxon matched-pairs test.

In order to test whether grey mouse lemurs move in space randomly, we applied a correlated random walk model (CRW) and compared the model's prediction for random movement with observed movement patterns. In contrast to the general random walk, the CRW takes correlations of turning angles of consecutive moves into account. These correlations in animal random walks result from an animal's preference for a certain direction about which there is random variance. We used the CRW as a null hypothesis to test whether this random variance can be found in mouse lemur movement. Kareiva and Shigesada (1983) proposed a formula that calculates expected squared net distances from a point of origin, over different spatial scales for a CRW. The basic assumption of this model is that in the case of a CRW, squared net distances tend to increase linearly with the number of consecutive moves (Kareiva and Shigesada 1983; Turchin 1998). The original formula can be reduced to a biologically relevant form because of equal probabilities that animals turn left or right:

$E\left(R_{n}^{2}\right)=n E\left(l^{2}\right)+2 E(l)^{2} \frac{c}{1-c}\left(n-\frac{1-c^{n}}{1-c}\right)$

$E\left(R_{n}^{2}\right)$ is the expected squared net distance in a CRW, $E(l)$ is estimated by the mean move length and $\mathrm{E}\left(l^{2}\right)$ is estimated by the mean squared move length, $c$ is $E(\cos \theta)$ where $\theta$ is the turning angle according to the clockwise measurement used by Kareiva and Shigesada (1983). Expected and observed squared net distances were calculated using Fractal 5 (Nams and Bourgeois 2004) for different scales, which were defined as different numbers of consecutive moves taken together (from a minimum of two steps per path to a maximum of the total number of steps in that path). Each observation bout was used for the calculation of movement paths (Table 1). Observed squared net distances were then compared to expected ones by means of a $t$-test for two dependent samples.

We also tested for the use of spatial memory to relocate feeding stations. If olfactory cues had been successfully excluded, spatial memory of the positions of feeding stations should be shown by evidence of retrieval. Therefore, all visits of stations were counted separately and analyzed in terms of success (visits of baited stations) and failure (visits of non-baited stations). Since the experimental design was such that all non-baited stations were formerly baited stations, all visits to these can be taken as indications of spatial memory. To examine whether spatial cues were the predominant cues used by the focal animals to relocate feeding stations, we considered an urn model used in probability theory to determine the probability of a given 
sequence of choices. For the choice of feeding stations, the probability of success $p$ is a factor $\kappa$ times the probability of failure $q$, i.e.

$p=\kappa q$

The probability of the observed sequences of success or failure for each animal can be computed for a given $\kappa$. Maximizing this probability with respect to $\kappa$ yields the maximum likelihood estimator of $\kappa$. A likelihood ratio test was then applied to test hypotheses about $\kappa$. The resulting test statistic is approximately Chi-squared distributed with one degree of freedom. Since one station was baited both for design I and II (Fig. 1), it had to be excluded from this analysis. Given the resulting equality in the number of baited and non-baited stations (3:3), we expected $\kappa$ to equal 1 in case of random choice. $\kappa$ was estimated for the datasets of design I (all bouts), the first bout after rotation to design II, and for all subsequent bouts of design II taken together. The computations were carried out using the software package R (Ihaka and Gentleman 1996). Visits per station were only counted once (first visit) to avoid any effect of repetition. Under the hypothesis of spatial memory, we expected $\kappa$ to be smaller than 1 for the first bout after rotation, due to a higher rate of errors in choice. In the case of olfactory cues (or other sensory cues) being the primary cue used by grey mouse lemurs to detect baited sites (provided that these were not sufficiently excluded), we expected $\kappa$ to be greater than 1 and not to differ between the two designs. The three resulting values for $\kappa$ were compared between the designs and, within design II, for difference from one, and difference from each other.

Furthermore, we tested whether mouse lemurs mentally represent space as a route-based network map. Since this mental representation is limited to a network of commonly reused routes, we predicted a restriction of the animals' movements to this network. To detect regularly used routes, angles of entry and exit across the border of a predefined target area were determined and tested for skewed distribution by means of circular statistics (Batschelet 1981). The target area was defined as a circular area of a $30 \mathrm{~m}$ radial distance around the central station no. 7. Points taken for analyses were the animal's last position before entry into the target area and the first one after the animal left this area. In order to detect possible spatial restrictions in grey mouse lemur movements, the positions of entry and exit were tested for clustering, using Rao's spacing test for angular concentration. This test was applied both for each design alone and over all designs taken together to investigate a probable influence of the experimental design on the use of common routes.

In order to test for possible Euclidean mapping, we conducted a release experiment. Since the presence of spatial memory is expected to increase foraging efficiency, we chose sequences of movements between known targets to investigate the capability of mouse lemurs to reduce travel distance during foraging. Five focal animals that could be re-trapped before the end of the study were released singly during the first hours of the night at the periphery of their respective home ranges, about $100 \mathrm{~m}$ from the closest area with feeding stations. By means of focal observations, positions of the released animals were recorded at least every minute until an ecologically salient target (e.g. feeding station, gum tree, tree hole) was reached. In order to evaluate movement efficiency, we calculated the ratio of the actual distance moved between two points divided by the shortest distance possible (according to Garber and Hannon's (1993) Index of Circuitry, abbreviated as CI) for recorded movements. Thus, a value of 1 signifies the most effective route, whereas a value of $n$ describes a path length $n$ times longer than the shortest route. We calculated CI values for individual movement segments between the point of release and the first target. In addition, mean angles, angular concentration as well as angular deviation were calculated for each individual to determine the degree of directedness in the animals' movements. Angles of direction were tested for deviation from random distribution by means of the Rayleigh test for randomness and further compared with the angle of the target axis (direct connection between point of release and target) using the $\mathrm{V}$ test (Batschelet 1981). One individual could be trapped in two consecutive nights and was therefore released twice, each time at different positions in such a way that once a baited and once a nonbaited station was closest. Movement paths were visualized in ArcView GIS 3.2 (Esri).

If not otherwise stated, all statistical tests were calculated with the software STATISTICA 6.0 (StatSoft Inc. 2001) with a significance level of $\alpha=0.05$.

\section{Results}

Spatial analyses

The mean area of overlap between kernels of the feeding stations and those of the animals' activity during observation increased between the pre-experimental phase and the experiment (Wilcoxon matched-pairs tests, $n=6 ; 50 \%$ kernels: $Z=2.20, P=0.028 ; 95 \%$ kernels: $Z=2.20$, $P=0.028$ ). Six out of seven focal animals shifted the centre of their activity range towards the stations during the experiment (Wilcoxon matched-pairs test, $n=6, Z=$ 2.20; $P=0.028$ ) (Table 2). One animal shifted the centre of its range away from the stations due to a general enlargement of its range during the mating season (design II). This animal, however, went on feeding at the stations in 
Table 2 Effects of the feeding experiment on the position of the weighted mean coordinates of home ranges and sleeping sites

\begin{tabular}{|c|c|c|c|c|c|}
\hline \multirow[t]{2}{*}{ Individual } & \multicolumn{2}{|c|}{$\begin{array}{l}\text { Weighted mean home } \\
\text { range }\end{array}$} & \multicolumn{3}{|c|}{ Sleeping trees } \\
\hline & Dist. before & Dist. after & $n$ & Dist. before & Dist. after \\
\hline \multirow[t]{2}{*}{ M2 } & 90.9 & 62.5 & 8 & 140.3 & 27.3 \\
\hline & & $58.1,67.0$ & & $133.3,140.3$ & $24.6,34.2$ \\
\hline \multirow[t]{2}{*}{ M3 } & 60.5 & 42.2 & 11 & 106.2 & 37.3 \\
\hline & & $30.8,67.3$ & & $71.1,117.8$ & $29.8,49.1$ \\
\hline \multirow[t]{2}{*}{ M4 } & $(53.5)$ & (123.5) & 10 & 30.5 & 25.9 \\
\hline & & $75.0,155.7$ & & $27.3,38.8$ & $25.9,27.3$ \\
\hline \multirow[t]{2}{*}{ M5 } & 70.6 & 16.9 & 11 & 93.5 & 51.6 \\
\hline & & $10.2,27.2$ & & $93.5,93.5$ & $24.9,52.8$ \\
\hline \multirow[t]{2}{*}{ M6 } & 27.9 & 17.7 & 4 & - & - \\
\hline & & $16.9,50.9$ & & & \\
\hline \multirow[t]{2}{*}{$\mathrm{F} 1$} & 64.9 & 39.4 & 12 & 55.0 & 38.8 \\
\hline & & $25.3,48.9$ & & $16.9,67.7$ & $22.2,85.3$ \\
\hline \multirow[t]{2}{*}{$\mathrm{F} 2$} & 16.3 & 14.4 & 8 & $(14.0)$ & $(27.4)$ \\
\hline & & $6.3,22.1$ & & $14.0,16.1$ & $17.1,35.2$ \\
\hline
\end{tabular}

Except total values for the weighted mean home range before the experiment, all values represent medians, with lower and upper quartiles in subscript. Values in brackets were excluded from analysis Dist. distance before and after onset of the experiment, respectively; $n$ number of different locations

region $\mathrm{M}$ at the beginning of its nightly activity and subsequently shifted its range towards the stations in region $\mathrm{R}$, where it could also be observed to feed. This animal was therefore excluded from the analysis.

Moreover, five out of six animals shifted the mean position of their sleeping sites towards the feeding stations (Wilcoxon matched-pairs test: $n=5, Z=2.02 ; P=$ 0.043) (Table 2). The only individual that showed a larger median distance after the onset of the experiment, as compared to before, already used a sleeping site in close proximity to the stations (14 $\mathrm{m}$ from the central station) and stayed in the area during the experiment.

\section{Tests for spatial memory}

Test for the usage of spatial cues

Applying a CRW model, we tested the basic assumption that grey mouse lemurs do not move in space randomly. For 34 out of 49 paths, squared net distances deviated significantly from those predicted by the CRW model (paired $t$-tests: $P<0.05$ ), indicating non-random movement; for the remaining 15 paths, no deviation from the model could be found (see Table S1 in ESM for details).

In order to test for spatial memory, the usage of baited and non-baited feeding stations was analyzed. Of special interest in terms of spatial memory were visits to feeding stations immediately after the change of the baiting pattern. Taking all observation bouts during design I together resulted in a maximum likelihood estimator $\kappa=13.0$, which indicates a very high accuracy in the choice of baited over non-baited stations. The null hypothesis, $\kappa=1$, can thus be rejected (Chi-squared test: $n=7$, $\left.\chi^{2}=9.257, P<0.001\right)$. For the first bout of design II, the maximum likelihood estimator was calculated as $\kappa=0.6$. This value differs from the previous $\kappa=13.0$ (Chi-squared test: $\left.n=5, \chi^{2}=23.106, P<0.001\right)$, but the hypothesis $\kappa=1$ cannot be rejected (Chi-squared test: $n=5$, $\left.\chi^{2}=0.725, P=0.395\right)$. For the remaining observation bouts of design II, the maximum likelihood estimate was $\kappa=3.8$. Here, the null hypothesis $\kappa=13.0$ cannot be rejected (Chi-squared test: $n=4, \chi^{2}=2.658, P=0.103$ ), but the null hypothesis $\kappa=1$ can be rejected (Chi-squared test: $\left.n=4, \chi^{2}=4.529, P=0.033\right)$. The highest probability of failure, i.e. the smallest value of $\kappa$, could thus be found right after the rotation of the baiting from design I to II (first bout), with an increase in accuracy over the following bouts.

To explore how spatial relationships are mentally represented in detail, we first analyzed movements across the borders of a pre-defined target area. For this purpose, a total of 74 points for design I and 71 points for design II (including 30 entries each) were analyzed for six and five animals, respectively. Four out of six animals showed a significant angular concentration of exchanges in certain directions over all designs (Rao's spacing test: $P<0.05$ ) (Table 3), indicating spatial restrictions of movements across the border of the target area. This was also the case for each design considered alone, except for one animal (F2) in design I. Visual inspection revealed that these angular concentrations were consistent over the two designs (Fig. 2).

\section{Test for spatial representation}

Release experiments were conducted with five animals. Since this experiment coincided with the mating season,

Table 3 Results of Rao's spacing test for angular concentration in movements across the border of the target area

\begin{tabular}{|c|c|c|c|c|c|c|c|c|c|}
\hline \multirow[t]{2}{*}{ Individual } & \multicolumn{3}{|c|}{ Design I } & \multicolumn{3}{|c|}{ Design II } & \multicolumn{3}{|c|}{ All designs } \\
\hline & $n$ & $U(\alpha)$ & $P$ & $n$ & $U(\alpha)$ & $P$ & $n$ & $U(\alpha)$ & $P$ \\
\hline M3 & 6 & 154.7 & $>0.1$ & 13 & 138.7 & $>0.1$ & 20 & 152.2 & $>0.1$ \\
\hline M4 & 13 & 168.3 & $<0.05$ & 4 & 211.0 & $<0.05$ & 18 & 177.7 & $<0.05$ \\
\hline M5 & 8 & 214.8 & $<0.01$ & 10 & 197.7 & $<0.01$ & 19 & 214.6 & $<0.01$ \\
\hline M6 & 10 & 148.5 & $>0.1$ & - & - & - & 10 & 148.5 & $>0.1$ \\
\hline F1 & 7 & 227.5 & $<0.01$ & 24 & 201.8 & $<0.01$ & 32 & 220.0 & $<0.01$ \\
\hline $\mathrm{F} 2$ & 18 & 161.1 & $>0.1$ & 15 & 176.0 & $<0.05$ & 34 & 176.8 & $<0.01$ \\
\hline
\end{tabular}

$n$ number of exchanges recorded, $U(\alpha)$ test statistic, $P$ probability 

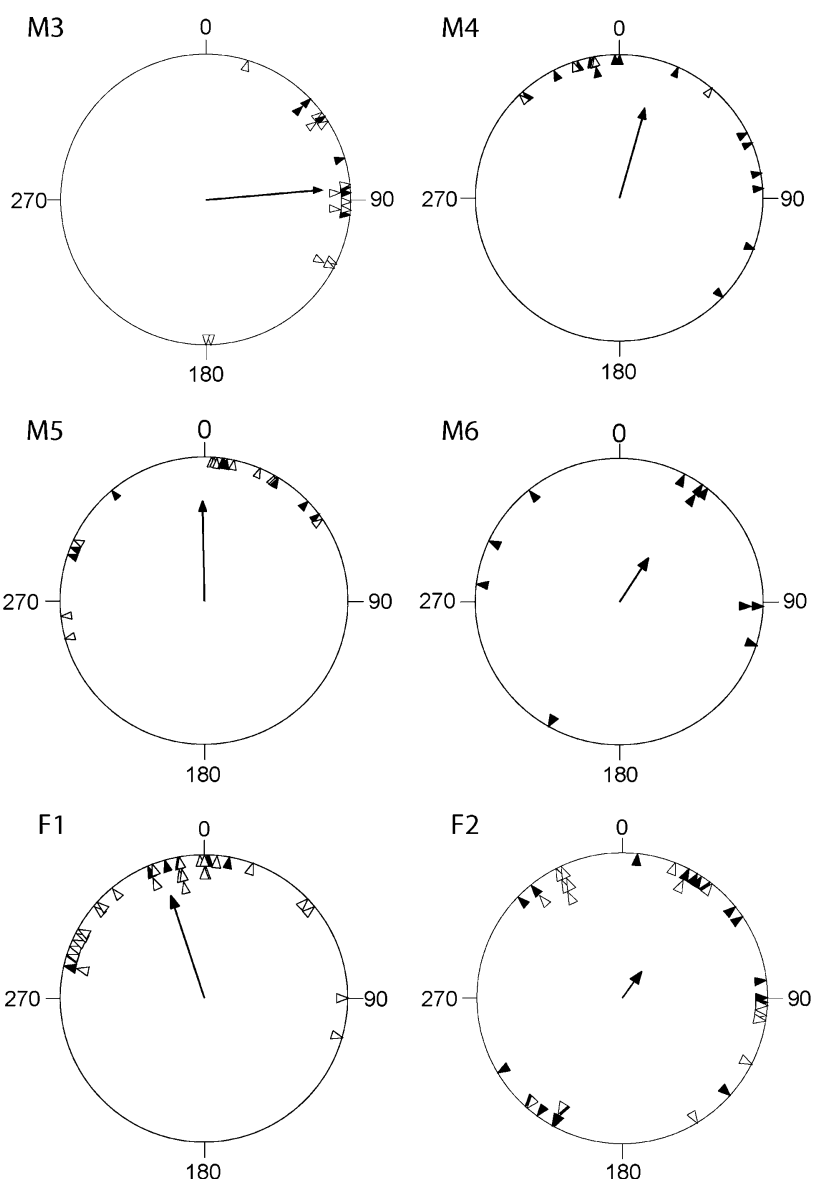

Fig. 2 Directions of exchange across the border of a circular target area for six individuals (M3, M4, M5, M6, F1, F2). Arrowheads indicate locations of exchange during design I (filled) and design II (open), central arrow shows the overall mean vector (length $r$ ). Degrees were adjusted to eastern direction set 0

two males (M1, M5) roamed widely outside their normal home ranges in search of receptive females. Because females did not represent fixed and predictable targets, these movement sequences were excluded from the analyses so that only four movement sequences from three animals could be analyzed. All movement sequences deviated in their angular concentration from a random distribution (Rayleigh test: $P<0.05$ ) and were clustered around the target axis (V test: $P<0.05$ ) (Table 4). CIvalues for travel efficiency were close to 1 , ranging from 1.03 to 1.30 . One animal (F2) did not directly move to a feeding station but approached a nearby gum tree where it fed instead. This tree was therefore defined as the target.

Figure 3 shows individual movements from the points of release to the first possible target and, in case of animal F2, to the first feeding station. Individual M3 chose a baited station that was slightly farther away than the nearest one, but chose a highly efficient route to get there $(\mathrm{CI}=1.03$, Table 4). Only one individual (M4, first trial) moved to the feeding station that was closest to the point of release (Fig. 3, start A). During a second trial, this individual chose the same station, even though it was not the closest one (Fig. 3, start B). With regard to the following travel direction including another station visit, however, this individual chose the shortest possible route.

\section{Discussion}

In the dry season, grey mouse lemurs face the problem of how to exploit sparsely distributed feeding sites efficiently. We investigated whether mouse lemurs use spatial cues for the relocation of such feeding sites and how accurately they do this in order to gain insights into how they represent spatial relationships mentally. The main results of this study were (1) that grey mouse lemurs did not move in space randomly, (2) that they used spatial cues to find food resources (baited feeding stations) in the absence of sensory cues, and (3) that they seemed to re-use a number of common routes to move about, but that they were nevertheless able to choose highly efficient routes with regard to travel distance.

\section{Spatial memory}

It is not surprising that grey mouse lemurs do not move randomly in space because this kind of movement is highly inefficient in exploiting widely scattered feeding sites (Garber and Hannon 1993; Garber 2000). Taking a short route between two points should be most economical and safe. Travel efficiency values (CI) of 1.03-1.30, with the lowest values for larger sample sizes, confirmed the general ability to shorten travel distances between goals in grey mouse lemurs. These values are comparable both to those calculated for tamarins $(\mathrm{CI}=1.18)$, for which the ability to maintain a detailed spatial map of the location and distribution of hundreds of feeding trees were proposed (Garber and Hannon 1993), as well as to those recently found for howler monkeys $(\mathrm{CI}=1.00-1.35$; Garber and Jelinek 2005) and spider monkeys $(\mathrm{CI}=1.25-1.67$; calculated from Valero and Byrne 2007). However, these values cannot reflect the actual routes mouse lemurs chose between feeding stations because (1) the observation protocol was restricted to one recording per minute due to difficulties in continuously monitoring a small, rapidly moving, nocturnal lemur, and because (2) Rao's spacing test of turning angles revealed that the animals did not consistently move directly forward. Thus, it is likely that focal animals actually travelled a longer distance than that conveyed by the small CI values.

One potential explanation for high travel efficiency in mouse lemurs is the role of the olfactory sense in directing 
Table 4 Results of 4 release experiments for 3 animals with fixed targets

\begin{tabular}{llcccccccccccc}
\hline Ind. & Target & $t(\mathrm{~min})$ & $n$ & $\begin{array}{l}\text { Shortest } \\
\text { dist. }(\mathrm{m})\end{array}$ & $\begin{array}{l}\text { Actual } \\
\text { dist. }(\mathrm{m})\end{array}$ & CI & $\begin{array}{l}\text { Target } \\
\text { axis }\left({ }^{\circ}\right)\end{array}$ & $\begin{array}{l}\text { Mean } \\
\text { angle }\left({ }^{\circ}\right)\end{array}$ & SD $\left(^{\circ}\right)$ & $r$ & $u(\alpha)$ & $P$ \\
\hline M3 & Station 1 & 9 & 10 & 105.2 & 108.5 & 1.03 & 258.0 & 251.2 & 21.4 & 0.93 & 3.92 & $<0.001$ \\
M4 & Station 3 & 9 & 10 & 91.0 & 100.3 & 1.10 & 188.0 & 141.3 & 46.6 & 0.67 & 1.72 & $<0.05$ \\
M4 & Station 3 & 8 & 8 & 99.0 & 112.2 & 1.13 & 158.8 & 145.8 & 81.0 & 0.79 & 2.67 & $<0.005$ \\
F2 & Gum tree & 17 & 16 & 85.3 & 111.3 & 1.30 & 316.5 & 312.8 & 56.7 & 0.51 & 2.78 & $<0.005$ \\
\hline
\end{tabular}

$I n d$. individual, $t$ time since release from trap, $n$ number of positions recorded (every minute), dist. travel distance, $C I$ index of circuitry, $S D$ mean angular deviation, $r$ length of the mean vector, $u(\alpha)$ test statistic (V test), $P$ probability

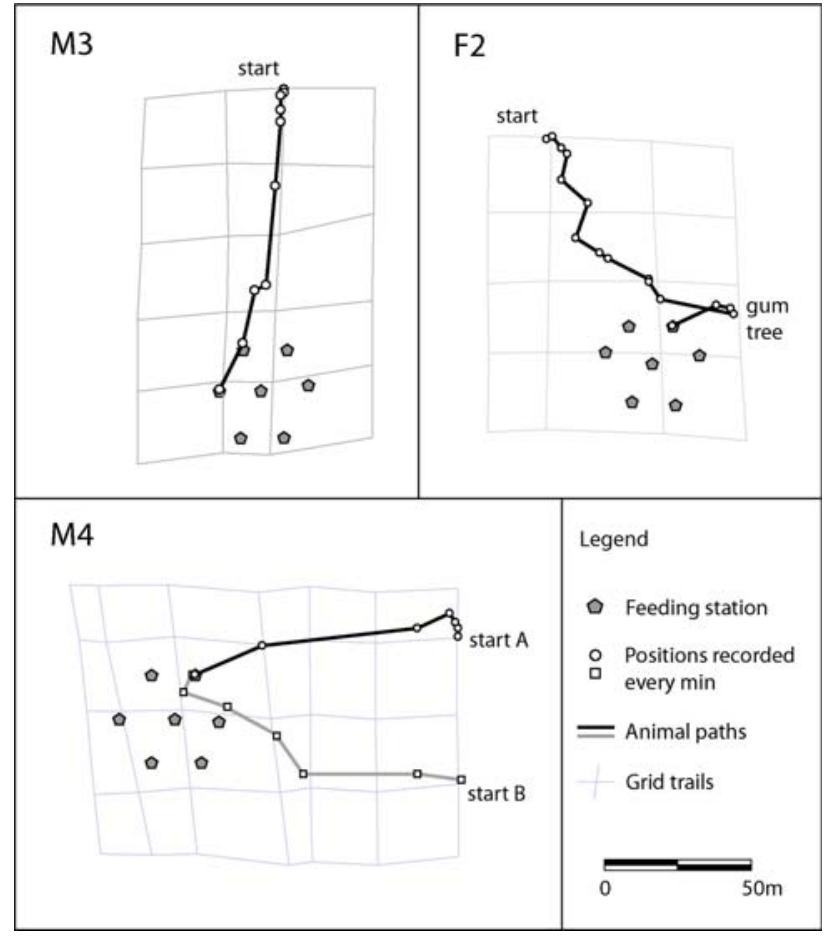

Fig. 3 Recorded movements after release of three individuals (M3, M4, F2) at the edge of their respective home ranges (start). Note that individual M4 was released twice (start $\mathrm{A}$ and $\mathrm{B}$ )

these movements. By likelihood analyses of feeding station visits we demonstrated indirectly, however, that odour or other sensory information were not the only cues used by mouse lemurs to detect resources. Moreover, the availability of sensory cues should have been the same for both designs, which should have led to similar accuracy during design II and therefore to a constantly high $\kappa$-value. Instead, $\kappa$ decreased to 0.6 for the first bout after change in the baiting pattern, which is smaller than chance, albeit not significantly different from random $(\kappa=1)$. This abrupt decrease in detection acuity indicates an abrupt invalidity of the cues the animals relied on before the change. However, since the focal animals' accuracy in the choice of baited feeding stations increased again during the following bouts of design II $(\kappa=3.8)$, indicating learning, they must have either shifted to an alternative cue or they already used other cues before. Spatial information is the only information that was changed by the time of this experiment and was thus made "unreliable", whereas sensory information should have always guided the animals towards baited feeding stations. The observed development of choice accuracy can therefore only be explained by the use of spatial cues to find baited feeding stations.

\section{Spatial representation}

Based on the finding that grey mouse lemurs rely at least partly on spatial memory in foraging decisions, it remains to be determined how this spatial information is represented mentally. We found a significant angular concentration in movements across a target area around the feeding stations, which was independent from the baiting pattern. This finding indicates a spatial restriction in the animals' movements, which may be found in other parts of their home ranges as well. This points to a route-based mental representation of spatial relationships of the environment in mouse lemurs resembling that recently proposed for other primate species (Di Fiore and Suarez 2007; Milton 2000; Noser and Byrne 2007). However, visual inspection of travel paths did not reveal a network of commonly used routes in a focal animal's home range.

Moreover, there is a fundamental restriction in space use for small arboreal species because they depend on branches to interconnect trees and to bridge open space (e.g. small rivers or paths). The part of Kirindy Forest where this study was conducted is characterized by a high number of small artificial clearings. Mouse lemurs have often been observed to rely on certain branches to cross a path limiting their movement and provoking detour (pers. observations). A high degree of angular concentration in a circular extract of the natural environment might therefore not be sufficient to show route-based network of their mental spatial representation. Moreover, the observed travel efficiency between stations reflects an ability of short-cutting by use of spatial information that cannot be explained by routebased encoding. In release experiments, three animals showed significant goal-directed movement and high travel 
efficiency with the lowest CI at 1.03 (highest efficiency). The distances travelled to reach the targets were larger than a home range radius and olfactory cues emitted by the targets should not have guided mouse lemurs over such a long distance. If mouse lemurs were restricted to a network of routes in their movement such goal-directed and flexibly responding travel would not be expected. Although sample size was small for the release experiment, results revealed a detailed knowledge of their home ranges and further confirmed main results for travel efficiency. Thus, mouse lemurs seem to have a mental representation of spatial relationships, which is more detailed than a route-based network map is generally assumed to be.

Novel path use can be explained by both path integration and a Euclidean map. The experimental design applied in this study did not allow investigation of path integration as a possible mechanism underlying spatial memory. Since mouse lemurs are no typical central place foragers and therefore do not necessarily return to a starting point, path integration is presumably not their predominant kind of spatial representation, though it might be one among multiple mechanisms used. Path integration has been discussed to be a prerequisite to develop more complex mental representations, such as the route-based map (Poucet 1993) or the cognitive map (Gallistel 1989, 1990; Gallistel and Cramer 1996), and may be used in conjunction with other mechanisms of spatial representation. To unambiguously demonstrate the existence of a cognitive map, a high level of experimental control is necessary, which can only be achieved under controlled conditions (e.g. maze experiments: Benhamou 1996; Morris 1981; Picq 1993).

The ability to find novel shortcuts to goals that are out of view may be achieved from the usage of odour cues in conjunction with simpler mechanisms of spatial memory. Near-optimal spatial performance may not necessarily require a cartographic-like map (Poucet 1993). Instead, mouse lemurs may represent space by storage of both sensory and spatial information as proposed by Poucet (1993). Accordingly, a network of common routes and olfactory or visual landmarks on a large scale is combined with a more detailed representation on smaller scales, requiring storage of detailed place representations only for essential resources within the animal's home range (e.g. feeding and sleeping sites). A representation of this kind does not require the storage of spatial information on global geometric relationships among features and needs not be permanently updated as the animal moves. It therefore represents an effective and economical mechanism on large spatial scales, presumably meeting major navigational demands of the grey mouse lemur.

High choice accuracy suggests that grey mouse lemurs rapidly learned a new spatial arrangement of baited feeding stations. Such a high accuracy and learning capability has been described in several experimental studies on spatial learning in haplorrhine primates (e.g. Garber 1989; Garber and Paciulli 1997; Menzel 1991; Menzel and Juno 1982). For instance, capuchin monkeys were shown to be able to discriminate between baited and non-baited stations after a single exposure to experimental feeding stations and adapted their foraging behaviour correspondingly (WinReturn/Lose-Shift foraging strategy; Garber and Paciulli 1997). Grey mouse lemurs might also possess a temporal memory allowing them to learn the renewal rates of their natural resources (e.g. the production of sugary secretions by homopteran larvae or gum flow of feeding trees). This assumption was supported by the observation of a temporal shift in some focal animals' feeding activity to earlier in the evening, whereas visits of stations later at night were rare, only once per station and of very short duration.

The development of error frequencies in station choice over time revealed a rapid learning capacity, although onetrial learning (Menzel and Juno 1982) could not be demonstrated here for grey mouse lemurs because we could not follow all focal animals over the entire night. This finding contradicts conclusions from a study conducted by Cooper (1978) who stated mouse lemurs to be "resistant to forgetting" (p. 943, see also Cooper 1980, p. 199). Such a conservative long-term memory would indeed be advantageous with regard to the spatial and temporal consistency of most of the resources they depend on, such as tree-holes as sleeping sites or food resources such as gum trees.

The observed flexibility and short-term adaptability can also be beneficial. During the wet season, fruits are an extensively used resource (Dammhahn and Kappeler 2008). Although fruit trees are fixed in space, and thus predictable, primates may base their ranging and foraging decisions on other information such as resource quality and productivity (e.g. Cunningham and Janson 2007; Garber 1989; Janson 1998; Janson and Byrne 2007). Menzel (1991) found that Japanese macaques are able to apply phenological information learned at one specific feeding patch to other patches of the same tree species. Whether strepsirrhine species possess the ability for an extrapolation of that kind remains unknown. However, with regard to knowledge concerning general fruit abundance, fruit quality and other variables such as exposition, predation risk and competition at the particular feeding site, it appears plausible that grey mouse lemurs benefit from learning and flexibly respond to changes in their natural environment.

Acknowledgments We acknowledge the authorization and support of this study by Prof. O. Ramilijaona and Prof. D. Rakotondravony (Département de Biologie Animale, Université d'Antananarivo), the Commission Tripartite and the CAFF of the Direction des Eaux et Forêts, the CFPF Morondava. We thank Dr. Rodin Rasoloarison, 
Léonard Razafimanantsoa, Tiana Andrianjanahary, Bruno Tsiveramana and the Equipe Kirindy for support and assistance in the field. Further thanks go to two anonymous reviewers and Prof. Richard W. Byrne for helpful comments on an earlier version of the manuscript and to Dr. Vilis O. Nams for comments on the use of CRW models. Financial support was kindly provided by the Deutsches Primatenzentrum (DPZ). All research reported in this manuscript is in compliance with animal care regulations and applicable national laws of Germany and Madagascar. All research protocols were approved by the appropriate Animal Use and Care committees of Germany (Bundesministerium für Naturschutz, BfN) and Madagascar (Ministère de l'Environment et des Eaux et Forêts, MINEEF).

Open Access This article is distributed under the terms of the Creative Commons Attribution Noncommercial License which permits any noncommercial use, distribution, and reproduction in any medium, provided the original author(s) and source are credited.

\section{References}

Altmann SA (1974) Baboons, space, time, and energy. Am Zool $14: 221-248$

Alyan S, Jander R (1994) Short-range homing in the house mouse, Mus musculus: stages in the learning of directions. Anim Behav 48:285-298

Anderson DJ (1983) Optimal foraging and the traveling salesman. Theor Popul Biol 24:145-159

Balda RP, Pepperberg IM, Kamil AC (1998) Animal cognition in nature. Academic Press, London

Batschelet E (1981) Circular statistics in biology. Academic Press, London

Benhamou S (1994) Spatial memory and searching efficiency. Anim Behav 47:1423-1433

Benhamou S (1996) No evidence for cognitive mapping in rats. Anim Behav 52:201-212

Bennett ATD (1996) Do animals have cognitive maps? J Exp Biol 199:219-224

Beran MJ, Beran MM, Menzel CR (2005) Spatial memory and monitoring of hidden items through spatial displacements by chimpanzees (Pan troglodytes). J Comp Psychol 119:14-22

Bicca-Marques JC, Garber PA (2004) Use of spatial, visual and olfactory information during foraging in wild nocturnal and diurnal anthropoids: a field experiment comparing Aotus, Callicebus, and Saguinus. Am J Primatol 62:171-187

Boesch C, Boesch H (1984) Mental map in wild chimpanzees: an analysis of hammer transports for nut cracking. Primates 25:160-170

Byrne RW (1979) Memory for urban geography. Q J Exp Psychol 21:147-154

Byrne RW (2000) How monkeys find their way: leadership, coordination, and cognitive maps of African baboons. In: Boinski S, Garber PA (eds) On the move: how and why animals travel in groups. The University of Chicago Press, Chicago, pp $491-518$

Cattet J, Etienne AS (2004) Blindfolded dogs relocate a target through path integration. Anim Behav 68:203-212

Collett TS, Collett M (2000) Path integration in insects. Curr Opin Neurobiol 10:757-762

Cooper HM (1978) Learning in prosimians. In: Chivers DJ, Herbert J (eds) Recent advances in primatology. Academic Press, New York, pp 941-944
Cooper HM (1980) Ecological correlates of visual learning in nocturnal prosimians. In: Charles-Dominique P, Cooper HM, Hladik A, Hladik CM, Pages E, Pariente GF, Petter-Rousseaux A, Schilling A, Petter J (eds) Nocturnal malagasy primates: ecology, physiology and behavior. Academic Press, New York, pp 191-203

Cramer AE, Gallistel CR (1997) Vervet monkeys as travelling salesmen. Nature 387:464

Cunningham E, Janson C (2007) Integrating information about location and value of resources by white-faced saki monkeys (Pithecia pithecia). Anim Cogn 10(3):293-304. doi:10.1007/ s10071-007-0077-4

Dammhahn M, Kappeler PM (2008) Comparative feeding ecology of sympatric Microcebus berthae and $M$ murinus. Int $\mathrm{J}$ Primatol 29(6):1567-1589

Di Fiore A, Suarez SA (2007) Route-based travel and shared routes in sympatric spider and woolly monkeys: cognitive and evolutionary implications. Anim Cogn 10(3):317-329. doi:10.1007/ s10071-006-0067-y

Dyer FC (1991) Bees acquire route-based memories but not cognitive maps in a familiar landscape. Anim Behav 41:239-246

Dyer FC (1994) Spatial cognition and navigation in insects. In: Real LA (ed) Behavioral mechanisms in evolutionary ecology. University of Chicago Press, Chicago, pp 66-98

Dyer FC (1996) Spatial memory and navigation by honeybees on the scale of the foraging range. J Exp Biol 199:147-154

Dyer FC, Berry NA, Richard AS (1993) Honey bee spatial memory: use of route-based memories after displacement. Anim Behav 45:1028

Erhart EM, Overdorff DJ (2008) Spatial memory during foraging in prosimian primates: Propithecus edwardsi and Eulemur fulvus rufus. Folia Primatol 79:185-196

Etienne A, Maurer R, Séguinot V (1996) Path integration in mammals and its interaction with visual landmarks. J Exp Biol 199:201209

Gallistel CR (1989) Animal cognition: the representation of space, time, and number. Annu Rev Psychol 40:155-189

Gallistel CR (1990) The organization of learning. MIT Press, Cambridge

Gallistel CR, Cramer AE (1996) Computations on metric maps in mammals: getting oriented and choosing a multi-destination route. J Exp Biol 199:211-217

Garber PA (1989) Role of spatial memory in primate foraging patterns: Saguinus mystax and Saguinus fuscicollis. Am J Primatol 19:203-216

Garber PA (2000) Evidence for the use of spatial, temporal, and social information by primate foragers. In: Boinski S, Garber PA (eds) On the move. The Chicago University Press, Chicago, pp 261-298

Garber PA, Hannon B (1993) Modeling monkeys: a comparison of computer generated and naturally occurring foraging patterns in two species of Neotropical primates. Int J Primatol 14:827-852

Garber PA, Jelinek PE (2005) Travel patterns and spatial mapping in Nicaraguan mantled howler monkeys (Alouatta palliata). In: Estrada A, Garber PA, Pavelka MSM, Luecke L (eds) New perspectives in the study of Mesoamerican primates: distribution, ecology, behavior, and conservation. Springer, New York, pp 287-309

Garber PA, Paciulli LM (1997) Experimental field study of spatial memory and learning in wild capuchin monkeys (Cebus capucinus). Folia Primatol 68:236-253

Gibson BM, Kamil AC (2001) Tests for cognitive mapping in Clark's nutcrackers (Nucifraga columbiana). J Comp Psychol 115:403417

Gónzalez-Gómez PL, Vásquez RA (2006) A field study of spatial memory in green-backed firecrown hummingbirds (Sephanoides sephaniodes). Ethology 112:790-795 
Healy SD, Hurly TA (1995) Spatial memory in rufous hummingbirds (Selasphorus rufus): a field test. Anim Learn Behav 23:63-68

Herz RS, Zanette L, Sherry DF (1994) Spatial cues for cache retrieval by black-capped chickadees. Anim Behav 48:343-351

Hooge P, Eichenlaub W, Solomon EK (1999) The animal movement program, version 1.1. USGS Alaska Biological Science Center, Anchorage

Ihaka R, Gentleman R (1996) R: a language for data analysis and graphics. J Comput Graph Stat 5(3):299-314

Janmaat KRL, Byrne RW, Zuberbühler K (2006) Evidence for a spatial memory of fruiting states of rainforest trees in wild mangabeys. Anim Behav 72:797-807

Janson CH (1996) Towards an experimental sociobiology of primates: examples for Argentine brown capuchin monkeys (Cebus apella nigritus). In: Norconk M, Rosenberger AL, Garber PA (eds) Adaptive radiation of Neotropical primates. Plenum Press, New York, pp 309-325

Janson CH (1998) Experimental evidence for spatial memory in foraging wild capuchin monkeys, Cebus apella. Anim Behav 55:1229-1243

Janson CH, Byrne R (2007) What wild primates know about resources: opening up the black box. Anim Cogn 10(3):357367. doi:10.1007/s10071-007-0080-9:1-11

Jenness J (2004) Weighted mean of points (weightmean.avx) Extension for ArcView 3.x, 1.2c

Joly M, Zimmermann E (2007) First evidence for relocation of stationary food resources during foraging in a strepsirrhine primate (Microcebus murinus). Am J Primatol 69:1-8

Kareiva PM, Shigesada N (1983) Analyzing insect movement as a correlated random walk. Oecologia 56:234-238

Langley CM (1994) Spatial memory in the desert kangaroo rat (Dipodomys deserti). J Comp Psychol 108:3-14

Loomis JM, Klatzky RL, Golledge RG, Cicinelli JG, Pellegrino JW, Fry PA (1993) Nonvisual navigation by blind and sighted: assessment of path integration ability. J Exp Psychol Gen 122:73-91

Menzel EW (1973) Chimpanzee spatial memory. Science 182:943945

Menzel CR (1991) Cognitive aspects of foraging in Japanese monkeys. Anim Behav 41:397-402

Menzel EW, Juno C (1982) Marmosets (Saguinus fuscicollis): are learning sets learned? Science 217:750-752

Menzel CR, Savage-Rumbaugh ES, Menzel EWJ (2002) Bonobo (Pan paniscus) spatial memory and communication in a 20hectare forest. Int J Primatol 23:601-619

Milton K (2000) Quo vadis? Tactics of food search and group movement in primates and other animals. In: Boinski S, Garber PA (eds) On the move. The University of Chicago Press, Chicago, pp 375-417

Morris RGM (1981) Spatial localization does not require the presence of local cues. Learn Motiv 12:239-260

Nams VO, Bourgeois M (2004) Fractal analysis measures habitat use at different spatial scales: an example with American marten. Can J Zool 82:1738-1747
Noser R, Byrne RW (2007) Mental maps in chacma baboons (Papio ursinus): using inter-group encounters as a natural experiment. Anim Cogn 10(3):331-340. doi:10.1007/s10071-006-0068-x

O'Keefe J, Nadel L (1978) The hippocampus as a cognitive map. Clarendon Press, Oxford

Picq JL (1993) Radial maze performance in young and aged grey mouse lemurs (Microcebus murinus). Primates 34:223-226

Poucet B (1993) Spatial cognitive maps in animals: new hypotheses on their structure and neural mechanisms. Psychol Rev 100:163182

Radespiel U (2006) Ecological diversity and seasonal adaptations of mouse lemurs (Microcebus spp.). In: Gould L, Sauther ML (eds) Lemurs: ecology and adaptation. Springer, New York, pp 211233

Rasoazanabary E (2006) Male and female activity patterns in Microcebus murinus during the dry season at Kirindy Forest, western Madagascar. Int J Primatol 27:437-464

Rensing S (1999) Immobilization and anaesthesia of nonhuman primates. Primate Rep 55:33-38

Séguinot V, Maurer R, Etienne AS (1993) Dead reckoning in a small mammal: the evaluation of distance. J Comp Physiol A 173:103113

Shettleworth SJ (1990) Spatial memory in food-storing birds. Philos Trans R Soc Lond B 329:143-151

Sorg JP, Rohner U (1996) Climate and tree phenology of the dry deciduous forest of the Kirindy Forest. Primate Rep 46:57-80

Sorg JP, Ganzhorn JU, Kappeler PM (2003) Forestry and research in the Kirindy Forest/Centre de Formation Professionelle Forestière. In: Goodman SM, Benstead JP (eds) The natural history of Madagascar. The University of Chicago Press, Chicago, pp $1512-1519$

StatSoft Inc. (2001) STATISTICA (data analysis software system), version 6

Swihart RK, Slade NA (1985) Testing for independence of observations in animal movements. Ecology 66:1176-1184

Thiele J, Winter Y (2005) Hierarchical strategy for relocating food targets in flower bats: spatial memory versus cue-directed search. Anim Behav 69:315-327

Tolman EC (1948) Cognitive maps in rats and men. Psychol Rev 55:189-208

Turchin P (1998) Quantitative analysis of movement: measuring and modeling population redistribution in animals and plants. Sinauer Associates, Sunderland

Valero A, Byrne RW (2007) Spider monkey ranging patterns in Mexican subtropical forest: do travel routes reflect planning? Anim Cogn 10(3):305-315. doi:10.1007/s10071-006-0066-z

Wang RF, Spelke ES (2002) Human spatial representation: insights from animals. Trends Cogn Sci 6:376-382

Wehner R (2003) Desert ant navigation: how miniature brains solve complex tasks. J Comp Physiol A 189:579-588

Wittlinger M, Wehner R, Wolf H (2006) The ant odometer: stepping on stilts and stumps. Science 312:1965-1967

Worton BJ (1989) Kernel methods for estimating the utilization distribution in home-range studies. Ecology 70:164-168 